\title{
Terminal Nucleotidyltransferase 5C
}

National Cancer Institute

\section{Source}

National Cancer Institute. Terminal Nucleotidyltransferase 5C. NCI Thesaurus. Code C96318.

Terminal nucleotidyltransferase 5C (391 aa, $45 \mathrm{kDa}$ ) is encoded by the human TENT5C gene. This protein is involved in the synthesis of mRNA poly(A) tails. 